under the sub-headings of size, external structures and internal structures.

There are author, taxonomic and subject indices, and each of the three chapters concludes with a comprehensive bibliography which will be invaluable to many readers; a rough calculation suggests that more than 1,800 scientific papers are cited.

The sub-title to the whole series is "A Comprehensive, Integrated Treatise on Life in Oceans and Coastal Waters". There seems little doubt, to judge from this first part, that the treatise will be comprehensive, but the success of the venture will depend on the extent to which it does indeed manage to integrate or synthesize the several parts and volumes into an ecological account. The present volume does not give grounds for confidence on this point. Indeed, the two chief factors dealt with here have been splintered in order to conform with the plan of the series. For example, the physiological and biochemical mechanisms of photosynthesis are excluded from the sub-chapter dealing with light in relation to plants. The account of light in relation to invertebrates also excludes a great deal of physiology and biochemistry which will be considered in later volumes along with topics such as morphology of photoreceptors, visual acuity, spectral sensitivity and bioluminescence. The venture on which Kinne has embarked is so large and ambitious that one must wonder whether the early volumes will be out of date before the final ones are published.

The charge that the book fragments ecology should not conceal its virtues; it is a major contribution to the literature of marine biology. Many of the sub-chapters are excellent reviews which will be read with great profit by students and research workers; I particularly liked N. G. Jerlov's short introduction to light in the sea, F. Gessner's and O. Kinne's sections on temperature in relation to plants and invertebrates, respectively, and J. H. S. Blaxter's sub-chapter on light in relation to fish.

In a treatise on ecology one expects a greater emphasis on populations and communities rather than organs and organisms but perhaps this will come in later volumes. The geographical aspects of ecology receive less attention than they deserve and the plankton gets less emphasis than the inshore and benthic organisms; but perhaps these are reflexions of the need for more work on biogeography and plankton in relation to light and temperature.

These two books will be used in quite different ways. Marine Food Chains will be most useful to experienced research workers; it will be invaluable to those who are planning their future research programmes. Marine Ecology is likely to be more useful for senior students and those just beginning their research careers but who among such people can afford at least seven and perhaps more volumes at the present price of $250 \mathrm{~s}$ each? Both volumes, however, should find a place in the libraries of universities and research institutes where they will be thoroughly used.

R. S. GLOVER

\section{Road to the Isles}

Patterns of Highland Development. By David Turnock. Pp. xviii $+272+32$ plates. (Macmillan: London, July 1970.) 160s.

SINCE the setting up of the Highlands and Islands Development Board in 1965, it has been widely acknowledged that special measures are necessary to tackle the problems of this lagging region of Britain in a realistic way; much of the Board's work could be said to confirm a central conclusion of this book-that under-development has been due less to poor resources and peripheral location than to shortcomings in the way these have been put to use.

$\mathrm{Mr}$ Turnock has taken on and in large measure achieved a formidable task - to review comprehensively and in historical perspective the facts about resource use, industry, tourism, employment, population, communications and rural and urban settlements in all the diverse and changing patterns which these make in this region. Furthermore he has attempted to reach at least tentative conclusions about a development strategy; a policy in which the promotion of further growth of industry and services at principal centres like Invergordon in the east and south is balanced by smaller development within reach of nodal points in the crofting west and north. His argument is at times uneven and inevitably ends in questions which perhaps only those involved in regional development could answer more firmly in terms of current feasibilities.

He throws a well informed historical light on such questions, intriguing in hindsight, as why the importance of forestry as a lasting resource was not seen at the time of the Clearances, why commercial fishing came to be exploited mainly by east coast men rather than at the better natural harbours of the west which are nearer the fisheries, why nodal centres with widely based employment are still poorly represented in some sub-regions and why it has taken government so long to recognize that development cannot be limited to crofting agriculture and must be multipurpose.

The story is informed by a wealth of field survey material, derived notably from the author's PhD thesis on Lochaber and stimulated, as he acknow- ledges, by O'Dell and Walton's classic geography of the region and other sources which are listed in a valuable twelve page bibliography. Thirty-two aptly chosen and annotated plates, mostly oblique air photographs, constitute an integral part of the work, as do thirty-two maps and diagrams, some of which, however, are on too small a scale to do justice to their content.

This is a valuable textbook and general reference and will be essential reading for those wishing to understand the present stage of development in the largest of Britain's rural regions.

F. D. N. Spaven

\section{Psychology of Behaviour}

Brain Mechanisms and Behaviour. An Outline of the Mechanisms of Emotion, Memory, Learning and the Organization of Behaviour, with particular regard to the Limbic System. By J. R. Smythies. Second edition. Pp. vi + 186. (Academic: New York, September 1970.) $61 s$.

IN a lucid and critical account of work on the limbic system, Dr Smythies outlines some physiological psychology and behavioural aspects of neurology for those clinical psychiatrists and neurobiologists to whom the brain is still merely a tissue.

The chief part of the first chapter has in eight pages an almost ideal prolegomenon for any newcomer to the study of brain mechanisms of behaviour-an array of qualifications and strictures on the interpretation of results using the present techniques. Nevertheless, of course, Smythies does not resist the temptation to try to make sense of the mass of available data. First he provides a digest of limbic system anatomy (with a few redundant diagrams, but otherwise unusually clear). Subsequent chapters summarize and attempt to integrate the results of selected experiments relating the behaviour of rat, cat, monkey and man to ablation, stimulation, macroelectrode recording and amine biochemistry. The contradictions and complexity are there, but the author is an admirable guide through the maze. $\mathrm{He}$ avoids behavioural and other jargon, although abbreviations often have to be decoded by context or by using a list found at the end of the chapter. Unit recording studies are hardly mentioned; studies of neuronal firing patterns in response to natural stimuli or in correlation with ongoing behaviour (with and without interference with the brain elsewhere) are very recent in the limbic system, however, and this book takes the literature up to 1968 .

The book is, in fact, the second edition of The Neurological Foundations of Psychiatry (1966). The change of 